\title{
Is the depression level the factor influencing the effectiveness of the group weight reduction program?
}

\author{
Magdalena Olszanecka-Glinianowicz ${ }^{1}$, Piotr Kocełak ${ }^{1}$, Wojciech Gruszka², Tomasz Wikarek ${ }^{1}$, \\ Piotr Dąbrowski ${ }^{1}$, Barbara Zahorska-Markiewicz ${ }^{3}$ \\ ${ }^{1}$ Health Promotion and Obesity Management Unit, Department of Pathophysiology, Medical University of Silesia \\ in Katowice, Poland \\ ${ }^{2}$ Student Scientific Association at the Department of Pathophysiology Medical University of Silesia in Katowice, Poland \\ ${ }^{3}$ Metabolic Management Clinic "WAGA", Katowice, Poland
}

\begin{abstract}
Introduction: The aim of the study was to assess the influence of the depression level on the effects of the group weight reduction program.

Material and methods: The study group involved 57 overweight and obese subjects [age $45.9 \pm 13.9$ years, body mass index (BMI) $35.5 \pm 5.4 \mathrm{~kg} / \mathrm{m}^{2}$ ]. All patients participated in a 3-month group weight reduction program. Body mass and height were measured and BMI was calculated, the depression level was assessed using Beck's Depression Inventory (BDI) at baseline and at the end.

Results: At baseline, the moderate depression level occurred in 8 women (BDI $23.1 \pm 3.0$ points), mild depression level in 22 subjects - 20 women and 2 men (BDI $13.4 \pm 2.4$ points) and 27 subjects -22 women and 5 men did not have features of depression (BDI $5.5 \pm 2.8$ points). Subjects with severe and mild depression levels were significantly older than these without features of depression $(p<0.005)$. We did not observe differences of BMI between study subgroups. There were no correlations between body mass and BMI, and the depression levels. The body mass and depression levels decreased significantly in all study subgroups after the group weight reduction program with psychotherapy. We observed a significant decrease in both body mass and depression level in all study subgroups. The mean weight reduction was similar in all study subgroups.
\end{abstract}

Conclusion: The depression level at baseline did not influence the effectiveness of the group weight reduction program.

Key words: weight loss, depression level, group weight reduction program.

\section{Introduction}

Numerous studies revealed an association between obesity and depression [1-3]. However, it is still unknown which of these diseases is the cause and which is the result. There are some hypotheses describing possible links between obesity and depression. One of these hypotheses suggests that obesity and depression are polygenic and heterogenic diseases, and their causes are partially genetic and conditioned also by environmental factors [4,5]. Possible pathophysiological links between obesity and depression comprise hyperactivation of the hypothalamus-hypophysis-adrenal axis [6], changes of sympathetic nervous system activation $[7,8]$, disturbance of neurotransmitter secretion [9-13] and immune activation [14-17].

It seems that there are forms of obesity and depression with a connection in the pathogenesis as well as forms without these links. As described above, trends of these relations may be different. It has already been proved that occurrence of depression may precede the development of obesity and, quite the reverse, the development of depression may follow development of obesity, moreover, both diseases may develop at the same time [4,5]. Our previous studies [18] revealed that in a population of 217 patients starting the group weight reduction program, the prevalence of depression reached 59\%. Numerous recent stud- 


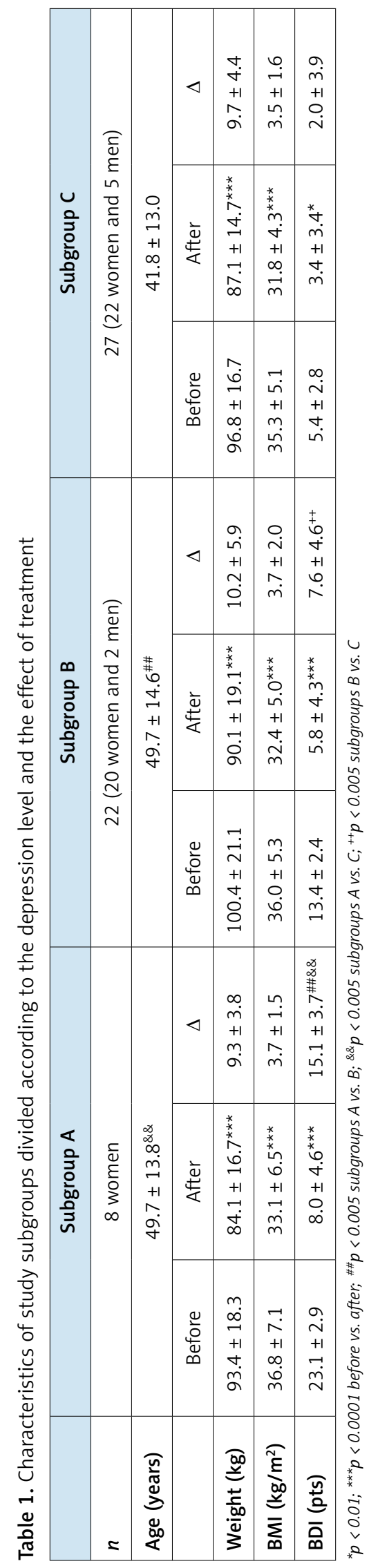

ies have reported that weight loss achieved with a lifestyle modification improved symptoms of depression [19-22]. On the other hand, depression may be one of the factors worsening the effects of weight reduction therapy. Therefore, the aim of the study was to assess the influence of the depression level on the effectiveness of the group weight reduction program.

\section{Material and methods}

The study group involved 57 overweight and obese subjects: 50 women and 7 men $[45.9 \pm 13.9$ years, body mass $96.7 \pm 18.2 \mathrm{~kg}$, body mass index (BMI) $\left.35.5 \pm 5.4 \mathrm{~kg} / \mathrm{m}^{2}\right]$.

All study subjects participated in a 3-month group weight reduction program (original program drawn up by Professor Zahorska-Markiewicz). The program consisted of a group instruction in behavioural and dietary methods of weight control carried out every two weeks and group psychotherapy using cognitive, behavioural and autohypnosis techniques. Subjects used a low fat diet with a deficit of $600-800 \mathrm{kcal} /$ day and aerobic physical exercises 30-40 $\mathrm{min} /$ day.

Body mass and height were measured and BMI was calculated. All subjects completed the Beck Depression Inventory (BDI) at baseline and at the end [23]. The score of less than 10 points was qualified as no depression, score of 10-18 points as a mild depression level, and above 1929 points as a moderate depression level and 30-69 points as a severe depression level.

The study was approved by the local Ethics Committee. All subjects gave their informed consent to the study.

\section{Statistical analysis}

All statistical analyses were performed with the use of Statistica 8.0 software. Results are presented as means \pm SD. The Mann-Whitney $U$ test was used for comparison between study subgroups. The results were considered as statistically significant with a $p$ value of less than 0.05 .

\section{Results}

On the basis of the BDI, study subjects were divided to three subgroups: A - moderate depression level, B - mild depression level and C - no depression. Subgroup A included 8 women (14.0\% of the study group), subgroup B - 22 subjects (20 women and 2 men) (38.6\%) and subgroup C -27 subjects (22 women and 5 men) (47.4\%). Subjects with mild and moderate depression levels were significantly older than these without depression. At baseline we did not observe differences in body mass and BMI between study subgroups. The depression levels decreased significantly in all subgroups. No differences in mean weight reduction between subgroups were found (Table 1). 
Table 2. Characteristics of study subgroups divided according to gender and the effect of treatment

\begin{tabular}{|c|c|c|c|c|c|c|}
\hline & \multicolumn{3}{|c|}{ Subgroup W } & \multicolumn{3}{|c|}{ Subgroup M } \\
\hline No. & \multicolumn{3}{|c|}{50} & \multicolumn{3}{|c|}{7} \\
\hline \multirow[t]{2}{*}{ Age (years) } & \multicolumn{3}{|c|}{$45.9 \pm 14.0$} & \multicolumn{3}{|c|}{$46.0 \pm 13.6$} \\
\hline & Before & After & $\Delta$ & Before & After & $\Delta$ \\
\hline Weight (kg) & $94.4 \pm 17.2$ & $85.1 \pm 15.8^{\star \star \star}$ & $9.3 \pm 4.5$ & $113.2 \pm 17.6$ & $101.4 \pm 13.6^{\star \star \star *}$ & $11.8 \pm 7.0$ \\
\hline BMI $\left(\mathrm{kg} / \mathrm{m}^{2}\right)$ & $35.4 \pm 5.5$ & $31.9 \pm 5.0^{\star \star *}$ & $3.5 \pm 1.7$ & $36.7 \pm 5.4$ & $32.9 \pm 4.2^{\star \star \star}$ & $3.8 \pm 2.3$ \\
\hline BDI (pts) & $12.1 \pm 8.7$ & $5.4 \pm 4.9^{\star * *}$ & $6.7 \pm 7.0$ & $8.7 \pm 2.9$ & $3.6 \pm 4.0^{\star \star \star}$ & $5.1 \pm 3.5$ \\
\hline
\end{tabular}

${ }^{\star * *} p<0.001$ before vs. after

Similar results were obtained when the study subjects were divided into gender-related subgroups: $\mathrm{W}$ - women and $\mathrm{M}-$ men. These subgroups are equal in terms of age, body mass and BMI. The depression level was not significantly higher in subgroup W than $M$. In both these subgroups the depression level and body mass decreased significantly at the end of the program (Table 2).

\section{Discussion}

As described above, numerous studies revealed links between obesity and depression. Our previous study [18] revealed that about $60.0 \%$ of obese subjects starting the group weight reduction program had mild or severe depression levels. Similar results were obtained in the present study (52.6\%). Similarly to results obtained recently $[24,25]$, the higher depression level was found among women than men.

Regardless of baseline depression levels and gender, we observed depression significant decrease after weight loss. It is difficult to clarify whether this decrease in depression levels are a cause of body mass reduction or are the effects of psychotherapy. Admittedly, previous studies show that weight loss is accompanied by a decrease in depression levels also in programs without psychotherapy but in some of them, patients took sibutramine. Therefore, it is also unclear whether the decrease in depression levels was the effect related to weight reduction only or mainly due to sibutramine stimulated serotonin neurons activity in brain [26,27]. Independently of factors that improved depression levels during weight loss, the high number of obese subjects with mild and severe depression symptoms suggests that psychotherapy is an important component of the obesity treatment.

Limited evidence suggests that depression is associated with poorer outcomes in behavioral weight loss programs. However, few studies revealed also that baseline depression levels did not influence the effectiveness of weight reduction therapy [26-30]. In our study, there were no differences in weight reduction when study subjects were grouped by moderate, mild and no depression levels. It should be emphasized that in terms of baseline body mass and BMI, these subgroups were similar. The results were also comparable when the criterion of identity was gender. Therefore, it seems that baseline depression levels did not disturb the weight reduction, although as observed previously, the depression level increased with severe obesity [17,27].

The limitation of our study is the size of the study group and its cross-sectional design.

In conclusion, the depression level at baseline did not influence the effectiveness of the group weight reduction program.

\section{Disclosure}

Authors report no conflict of interest.

\section{References}

1. Roberts RE, Kaplan GA, Shema SJ, Strawbridge WJ. Are the obese at greater risk for depression? Am J Epidemiol 2000; 152: 163-170.

2. Roberts RE, Deleger S, Strawbridge WJ, Kaplan GA. Prospective association between obesity and depression: evidence from the Alameda County Study. Int J Obes Relat Metab Disord 2003; 27 : 514-521.

3. Ross CE. Overweight and depression. J Health Soc Behav 1994; 35: 63-79.

4. McElroy SL, Kotwal R, Malhotra S, Nelson EB, Keck PE, Nemeroff $\mathrm{CB}$. Are mood disorders and obesity related? A review for the mental health professional. J Clin Psychiatry 2004; 65: 634-651.

5. Rosmond R. Obesity and depression: same disease, different names? Med Hypotheses 2004; 62: 976-979.

6. Adam TC, Epel ES. Stress, eating and the reward system. Physiol Behav 2007; 24: 449-458.

7. Veith RC, Lewis N, Linares OA, et al. Sympathetic nervous system activity in major depression. Basal and desipramine - induced alterations in plasma norepinephrine kinetics. Arch Gen Psychiatry 1994; 51: 411-422.

8. Davy KP. The global epidemic obesity: are we becoming more sympathetic? Curr Hypertens Rep 2004; 6: 241-246.

9. Redrobe JP, Dumont Y, Quirion R. Neuropeptide Y (NPY) and depression: from animal studies to the human condition. Life Sci 2002; 71: 2921-2937.

10. Strömbom U, Krotkiewski M, Blennow K, Månsson JE, Ekman R, Björntorp P. The concentrations of monoamine metabolites and 
neuropeptides in the cerebrospinal fluid of obese women with different body fat distribution. Int J Obes 1996; 20: 361-368.

11. Lambert GW, Vaz M, Cox HS, et al. Human obesity is associated with chronic elevation in brain 5-hydroxytryptamine turnover. Clin Sci (Lond) 1999; 96: 191-197.

12. Wang GJ, Volkow ND, Logan J, et al. Brain dopamine and obesity. Lancet 2001; 357: 354-357.

13. Zahorska-Markiewicz B, Obuchowicz E, Waluga M, Tkacz E, Herman ZS. Neuropeptide $Y$ in obese women during treatment with adrenergic modulation drugs. Med Sci Monit 2001; 7: 403-408.

14. Miller GE, Rohleder N, Stetler C, Kirschbaum C. Clinical depression and regulation of the inflammatory response during acute stress. Psychosom Med 2005; 67: 679-687.

15. Olszanecka-Glinianowicz M, Zahorska-Markiewicz B, Janowska J, Zurakowski A. Serum concentrations of nitric oxide, TNF-a and TNF soluble receptors in women with overweight and obesity. Metabolism 2004; 53: 1268-1273.

16. Olszanecka-Glinianowicz M, Zahorska-Markiewicz B, Janowska J, Kocełak P, Holecki M. Increased concentrations of interleukin- 6 (IL-6) is related to obesity but not insulin-resistance. Pol J Endocrinol 2004; 55: 437-441.

17. Olszanecka-Glinianowicz M, Zahorskamarkiewicz B, Kocełak P, et al. Depression in obese persons before starting complex group weigh-reduction programme. Int I Soc Psychiatry 2009; 55: 407-413.

18. Olszanecka-Glinianowicz M, Zahorska-Markiewicz B, Kocełak P, et al. Is chronic inflammation a possible cause of obesity-related depression? Mediators Inflamm 2009; 2009: 439107.

19. Gladis MM, Wadden TA, Vogt R, Foster G, Kuehnel RH, Bartlett SJ. Behavioral treatment of obese binge eaters: do they need different care? J Psychosom Res 1998; 44: 375-384.

20. Wadden TA, Butryn ML, Byrne KJ. Efficacy of lifestyle modification for long-term weight control. Obes Res 2004; 12 (Suppl): 151S-162S.

21. Wadden TA, Foster GD, Letizia KA. One-year behavioral treatment of obesity: comparison of moderate and severe caloric restriction and the effects of weight maintenance therapy. J Consult Clin Psychol 1994; 62: 165-171.

22. Wing RR, Epstein LH, Marcus MD, Kupfer DJ. Mood changes in behavioral weight loss programs. J Psychosom Res 1984; 28: 189-196.

23. Lasa L, Ayuso-Mateos JL, Vázquez-Barquero JL, Díez-Manrique FJ, Dowrick CF. The use of the Beck Depression Inventory to screen for depression in the general population: a preliminary analysis. J Affect Disord 2000; 57: 261-265.

24. Becker E, Margraf J, Turke V, Soeder U, Neumer S. Obesity and mental illness in a representative sample of young women. Int J Obes Relat Metab Disord 2001; 25 (Suppl 1): S5-S9.

25. Carpenter K, Hasin D, Allison D, Faith M. Relationship between obesity and DSM-IV major depressive disorder, suicide ideation, and suicide attempts: results from a general population study. Am J Pub Health 2000; 90: 251-257.

26. Faulconbridge LF, Wadden TA, Berkowitz Rl, et al. Changes in symptoms of depression with weight loss: results of a randomized trial. Obesity (Silver Spring) 2009; 17: 1009-1016.

27. Dixon JB, Dixon ME, O'Brien PE. Depression in association with severe obesity: changes with weight loss. Arch Intern Med 2003; 163: 2058-2065.

28. Dove ER, Byrne SM, Bruce NW. Effect of dichotomous thinking on the association of depression with $\mathrm{BMI}$ and weight change among obese females. Behav Res Ther 2009; 47: 529-534.

29. Pagoto S, Bodenlos JS, Kantor L, Gitkind M, Curtin C, Ma Y. Association of major depression and binge eating disorder with weight loss in a clinical setting. Obesity (Silver Spring) 2007; 15: 2557-2559.
30. Ludman E, Simon GE, Ichikawa LE, et al. Does depression reduce the effectiveness of behavioral weight loss treatment? Behav Med 2010; 35: 126-134. 